\title{
York Mason Procedure to Repair Iatrogenic Rectourinary Fistula
}

\author{
Jonathan Efron
}

Published online: 1 October 2013

(c) Société Internationale de Chirurgie 2013

A rectourethral fistula is a devastating complication of prostatectomy that is difficult to treat and may have significant implications for the patient with respect to quality of life after repair. Falavolti and colleagues have reviewed and published their results in employing the York Mason approach to repair of these fistulas [1]. As they so aptly describe, the surgical approach to rectourethral fistula varies and is often related to the etiology of the fistula. Fistulas that are the result of an iatrogenic injury at the time of prostatectomy are small and more easily managed than those caused by severe prostate and rectal necrosis secondary to radiation therapy for prostate cancer. Therefore the method of surgical repair varies.

Hechenbleikner et al. [2] in a recent literature review on rectourethral fistula repair, identified four primary approaches to repairing these defects: transanal, transabdominal, trans-sphincteric, and transperineal. Now, we can clearly add the York Mason approach to that list. However, the overall results from the York Mason approach described are not as promising as those seen with more traditional repairs. The authors report only a $50 \%$ success rate, which compares to a $90 \%$ closure rate when using a transperineal approach [2]. The transperineal approach uses an interposition graft of either muscle, usually the gracilis muscle from the leg, or a buchal mucosal flap, which is not described with the York Mason technique. The transperineal or transanal approach also has the added benefit of not dividing the anal sphincter muscles, which may alter longterm fecal continence in patients. The authors of the present study have a large percentage of patients who have undergone more that two repairs before seeking their services,

J. Efron $(\bowtie)$

Johns Hopkins University School of Medicine, Baltimore, MD, USA

e-mail: jefron1@jhmi.edu and this must be taken into account when reviewing the data they report with the York Mason approach. This York Mason technique may provide a clean nonviolated approach to the fistulous tissue after prior repairs have been attempted, and therefore perhaps this technique should be reserved for patients who have failed transanal or transperineal repairs. The addition of a flap such as the buchal mucosal flap to the York Mason approach may add further benefit and result in higher success rates.

The factors that determine whether a patient with a rectourethral fistula will undergo a definitive local repair or an excision with either permanent fecal or urinary diversion include the degree of tissue destruction, the etiology of the fistula, and the continence of both systems. Small defects in patients who have maintained urinary control are still best served by the transperineal approach with gracilis or other muscle interposition. Those with significant tissue destruction and loss of continence may be best served with permanent urinary diversion and either fecal diversion, if they have poor sphincter function, or repair of the rectal defect. Those with severe radiation proctitis as a cause of fistula may require a proctectomy, but they may also be candidates for coloanal anastomosis. For those that have had failed traditional repairs and recurrence, and who wish to maintain urinary function, the York Mason approach may be the best bet for obtaining successful closure.

\section{References}

1. Falavolti C, Sergi F, Shehu E et al (2013) York Mason procedure to repair iatrogenic rectourinary fistula: our experience. World $\mathrm{J}$ Surg. doi:10.1007/s00268-013-2199-y

2. Hechenbleikner E, Buckley JC, Wick EC (2013) Acquired rectourethral fistulas in adults: a systematic review of surgical repair techniques and outcomes. Dis Colon Rectum 56:374-383 